\title{
O DIREITO AMBIENTAL NA SALA DE AULA: SIGNIFICADOS DE UMA PRÁTICA EDUCATIVA NO ENSINO MÉDIO
}

\section{Environmental law at classroom: meanings of an educational practice in High School level}

\author{
Carmen Roselaine de Oliveira Farias ${ }^{1}$ \\ Washington Luiz Pacheco de Carvalho ${ }^{2}$
}

\begin{abstract}
Resumo: Neste trabalho, apresentamos um determinado evento de Educação Ambiental realizado no âmbito do Ensino Médio. Por meio do estudo e da transformação de um caso judicial ambiental em material educativo, foi proposto um minicurso sobre os impactos socioambientais decorrentes da formação do reservatório da Usina Hidrelétrica Três Irmãos, construída no curso do rio Tietê, no interior do Estado de São Paulo (Brasil). O objetivo geral da pesquisa foi analisar as potencialidades deste caso de Direito Ambiental para subsidiar práticas de Educação Ambiental. O minicurso baseouse em aulas dialogadas, trabalhos em grupos e dramatizações. Ao final, foram realizadas entrevistas com os alunos participantes a fim de se compreenderem os significados atribuídos por eles a esse evento; e, pela análise fenomenológica, foi possível construir e discutir algumas perspectivas educativas para tratar do Direito Ambiental na escola.
\end{abstract}

Palavras-chave: Educação ambiental. Direito ambiental. Ensino Médio.

\begin{abstract}
In this paper we present an experience related to environmental education that was accomplished with high school students. The educational material based on the legal process, was offered to high school students in a short term course in which the content was about the social and environmental impacts caused by the creation of the water reservoir at the Três Irmãos Hydroelectric Power Plant, that was built in the Tietê river, in the State of São Paulo, in Brazil. The main focus of the research was to analyze the potential of this case of environmental rights in order to support the educational practice within environmental education. The short term course was based on dialogued in the classes, working groups and dramatizations. By the end of the activities interviews were made with the students aiming to comprehend the meanings given by them of the whole educational experience. The analysis of these interviews, by a phenomenological approach, made it possible to construct and to discuss some perspectives that seemed potentially useful in exploring environmental rights at the basic school level.
\end{abstract}

Key words: Environmental education. Environmental law. High School.

\footnotetext{
${ }^{1}$ Mestre em Educação para a Ciência, doutoranda, Programa de Pós-Graduação em Educação, Universidade Federal de São Carlos (UFSCar). São Carlos, SP. < crfarias@yahoo.com.br>

${ }^{2}$ Professor adjunto, Departamento de Física e Química, Faculdade de Engenharia de Ilha Solteira, Universidade Estadual Paulista (Unesp). Ilha Solteira, SP. <washcar@dfq.feis.unesp.br>
}

${ }^{1}$ Rua Nove de Julho, 2757

Jardim Lutfalla II

São Carlos, SP

$13.560-560$

157

Ciência \&̊ Educação, v. 13, n. 2, p. 157-174, 2007 
Farias, C. R. O.; Carvalho, W. L. P.

\section{Introdução}

A temática ambiental surge na sociedade contemporânea permeando vários campos do conhecimento e repercutindo de forma significativa nos propósitos da educação escolar. Neste sentido, freqüentemente, a Educação Ambiental (EA) é apontada como um dos principais caminhos para a formação de pessoas capazes de lidar com os problemas e conflitos socioambientais para que estejam preparadas para a compreensão dos debates científicos e tecnológicos implicados nessas questões.

De acordo com Carvalho (2002), a EA na América Latina e no Brasil, em particular, tem sido concebida em sintonia com a crítica socioambiental sustentada pelos movimentos ambientalistas e difundida na sociedade, o que a torna originária de um campo social historicamente construído denominado de campo ambiental. Essa filiação confere à EA uma tradição de crítica à sociedade, ao modo de vida e à forma tradicional de educar, o que não significa pertencer a um campo de significação homogêneo. Ao contrário, o ideário ambientalista configura um vasto leque de orientações éticas e políticas e, da mesma forma, a educação apresenta várias vertentes, o que tem contribuído para a elaboração dos vários sentidos atribuídos à $\mathrm{EA}$.

Atualmente, a EA consolida uma das principais ênfases de propostas curriculares e associa-se à formação da cidadania, considerada uma das principais tendências crescentemente incentivadas no decorrer da década de 1990 (LAYRARGUES, 1999). No mesmo sentido, o enfoque nas relações entre Ciência, Tecnologia e Sociedade (CTS) procura alargar o horizonte do ensino de Ciências, enfatizando aspectos socioambientais da Ciência e Tecnologia e avançando no trânsito entre perspectivas de duas culturas: a científico-tecnológica e a humanística (CARVALHO, 2005). Especialmente neste campo disciplinar, observa-se o movimento no sentido de comprometer a educação escolar com valores humanos e éticos, ampliando seu escopo educativo e social. Esta dimensão leva-nos a supor a existência de uma maior articulação da educação escolar com a temática dos direitos, sobretudo dos direitos coletivos emergentes, como, por exemplo, os ambientais que, cada vez mais, passam a fazer parte das preocupações e práticas de inúmeros profissionais, entre os quais professores e educadores ambientais envolvidos com a formação da cidadania em todos os níveis de ensino.

De acordo com Santos (2004), nas últimas duas décadas, os códigos de cidadania atingiram grande proeminência, levando várias comunidades do mundo a enfrentar o atual déficit de cidadania nos sistemas educacionais. Daí fóruns de política internacional assumirem como alta prioridade o desenvolvimento de uma "educação para a cidadania democrática fundada nos direitos e responsabilidades dos cidadãos" (SANTOS, 2004, p. 13).

No Brasil, atribui-se à educação básica a formação para o exercício da cidadania, ao propor-se um currículo que tenha vínculos com as diversas dimensões da vida dos alunos e voltado a um ensino contextualizado e fundamentado na interdisciplinaridade. No ensino fundamental, as temáticas relacionadas à cidadania (Meio Ambiente, Ética, Diversidade Cultural, Sexualidade) foram previstas de forma transversal a todas as áreas disciplinares. $\mathrm{O}$ tema "meio ambiente", incluído nos Parâmetros Curriculares Nacionais (PCN), pretende "contribuir para a formação de cidadãos conscientes, aptos a decidirem e atuarem na realidade socioambiental de um modo comprometido com a vida, com o bem-estar de cada um e da sociedade local e global" (BRASIL, 1998a, p. 11).

No Ensino Médio, os PCN assentam seus fundamentos sobre dois fatores relaciona- 
dos entre si: o econômico, marcado pela emergência de novas tecnologias e que influencia a organização do trabalho e as relações sociais; e a denominada "revolução informática", que acarretou profundas mudanças no campo do conhecimento. De forma geral, estes parâmetros consideram que a "formação do aluno deve ter como alvo principal a aquisição de conhecimentos básicos, a preparação científica e a capacidade de utilizar as diferentes tecnologias relativas às áreas de atuação" (BRASIL, 1998b, p. 6).

Neste sentido, pelo menos no plano formal, a educação como formação da cidadania tem constituído relações com a formação em direitos e responsabilidades dos cidadãos em face da complexidade da sociedade atual. Entretanto, o termo cidadania abriga múltiplas concepções e conceitos afins, variando no tempo e no espaço, conforme interpretações mais restritas ou mais amplas, e traduzindo acordos e desacordos políticos e sociais.

Entre as diferentes concepções de cidadania, tornou-se clássica a concepção de Marshall (1967) que, ao analisar o caso inglês, constituiu uma noção evolutiva da cidadania pela emergência de direitos civis e políticos, chamados de primeira geração; direitos sociais, de segunda geração; e, a partir da segunda metade do século XX, direitos de terceira geração, referentes aos interesses difusos, como os direitos ambientais, dos consumidores, das coletividades étnicas ou da própria humanidade. Atualmente, fala-se em direitos de quarta geraşão relacionados à bioética e à manipulação tecnológica de formas de vida (VIEIRA, 1997).

Procurando estabelecer marcos de construção histórica do conceito de cidadania, Santos (2004) reconhece três tradições principais: a cidadania clássica, relacionada à tradição aristotélica, e que enfatiza a participação política na vida pública; a cidadania moderna, referente aos direitos individuais e de propriedade; e a cidadania pós-moderna, que tem como valor guia a solidariedade e se embasa nos direitos de terceira geração. Estas tradições podem ser vistas sincronicamente, ou seja, coexistem nos dias de hoje e se estendem desde entendimentos mais restritos, que identificam cidadania a um estatuto excessivamente legalista, até concepções mais abrangentes e práticas de uma cidadania menos homogênea e que respeita a identidade cultural de grupos diferenciados.

No campo educativo, particularmente no da EA, entende-se que a cidadania tem se articulado a determinadas visões de Direito Ambiental, ao qual é atribuída a função de auxiliar na resolução de problemas e conflitos associados às formas socialmente diferenciadas de acesso e uso dos bens ambientais. Acredita-se que esta é uma interface de relevância para a EA, visto que, ao enfatizar a dimensão política e, portanto, jurídica da questão ambiental, contribui para aprofundar a reflexão não só quanto às atuais relações entre sociedade e ambiente, mas também sobre os instrumentos de que dispomos para a garantia e a defesa dos direitos ambientais.

\section{Questões de pesquisa}

As interfaces percebidas entre Direito Ambiental e EA constituíram o ponto de partida deste trabalho, que se propôs a procurar possibilidades e potencialidades do tratamento educativo de temas jurídico-ambientais no âmbito do Ensino Médio. A questão que norteou esta pesquisa foi a seguinte: quais os significados atribuidos por alunos do Ensino Médio a uma vivência educativa que envolven o estudo e a dramatização de um caso judicial ambiental? Além desta questão, 
Farias, C. R. O.; Carvalho, W. L. P.

outras também fizeram parte do percurso da pesquisa, tais como: qual o potencial educativo de um caso judicial sobre um dano ambiental? O que envolve a tentativa de se transformar um processo judicial em um material educativo para a $\mathrm{E} A$ ? Que papel a dramatização desempenha no tratamento educativo do Direito Ambiental? Quais perspectivas educativas podem ser delineadas valendo-se de uma análise fenomenológica derivada de discursos de alunos que vivenciaram uma intervenção educativa jurídico-ambiental?

\section{O fenômeno educativo investigado}

Descrevemos o fenômeno educativo investigado com base em dois aspectos: o primeiro relativo ao estudo de um caso judicial ambiental que subsidiou a experiência educativa; e o segundo referente à vivência educativa propriamente dita.

O caso judicial ambiental escolhido foi o processo n. 97/90, que tramitou na Primeira Vara Cível da Comarca de Pereira Barreto, interior do Estado de São Paulo, em que foi autor o Ministério Público do Estado de São Paulo e ré a Companhia Energética do Estado de São Paulo (CESP), onde se encontra arquivado desde 1998. A questão controversa, neste caso, referiu-se aos impactos socioambientais causados pela formação do reservatório da Usina Hidrelétrica (UHE) Três Irmãos, ocorrida na década de 1990. Optou-se por este processo judicial específico por tratar de uma problemática bastante presente na realidade brasileira e regional do Estado de São Paulo. Além disso, considera-se que o Direito Ambiental, quando tratado na perspectiva de sua aplicação em um conflito socioambiental real, torna-se mais significativo para os sujeitos que lhe atribuem significados, sobretudo se estivermos diante de objetivos educativos. O estudo deste caso judicial implicou, além da seleção de textos do processo judicial e análise interpretativa, a sua transformação em um material didático que foi, posteriormente, utilizado para subsidiar uma intervenção educativa com alunos do Ensino Médio.

O segundo aspecto diz respeito ao minicurso realizado com um grupo de alunos de Ensino Médio da Escola Estadual de Urubupungá, situada em Ilha Solteira, interior do Estado de São Paulo. Neste evento, foi utilizada, entre outras estratégias educativas, a dramatização do caso judicial como instrumento de construção ativa e coletiva de conhecimento. Alguns alunos participantes foram entrevistados e suas descrições foram submetidas à análise fenomenológica, com vistas à interpretação dos significados que atribuíram a esse evento. Neste trabalho, procuramos aferir algumas potencialidades e limitações atinentes a nossa experiência, mantendo o caminho aberto para futuras investigações que poderão ampliar as reflexões aqui iniciadas.

\section{O estudo do caso judicial para uso educativo: considerações sobre a trajetória metodológica}

O estudo de caso não se confunde com o uso educativo do caso. Enquanto o primeiro visa, geralmente, atender às necessidades da pesquisa, o segundo compromete-se diretamente com os objetivos da educação. No âmbito do estudo de caso, não há a pretensão de atingir ou corroborar conhecimentos considerados como verdades universais, mas buscar relações que existem entre as partes e o todo e que caracterizam o contexto focalizado. Na nossa perspectiva, os pressupostos do estudo de caso foram abordados de maneira flexível, tendo-se em 
vista o uso do processo judicial como unidade de análise. A escolha por esse material decorreu do objetivo de se abordar, detalhadamente, esse caso com base em uma fonte potencialmente rica em documentos e discursos variados.

Salienta-se que os casos judiciais ambientais são casos reais que, entre outras características, expressam a forma pela qual nossa sociedade soluciona juridicamente conflitos socioambientais. Consideramos que neles há um potencial para a educação pelo fato de apresentarem diversas perspectivas sobre um mesmo conflito de interesses e direitos, bem como elementos diversos provenientes da cultura jurídica. Neste sentido, valendo-se de um processo judicial ambiental é possível identificar várias perspectivas, como, por exemplo: as pretensões das partes, interpretações do direito ambiental, questionamentos de natureza ética e moral, perspectivas técnico-científicas, decisões judiciais, além das repercussões sociais e públicas relativas à controvérsia. Além disso, é possível também explorar a relação entre conteúdo e forma na aplicação do Direito Ambiental, visto que o direito estatal determina a obediência a uma série de ritos e procedimentos que dizem respeito à instauração e manutenção do processo, defesa e produção de provas, assim como os recursos cabíveis diante da inconformidade das partes perante as decisões judiciais proferidas. Todos estes procedimentos também significam, de certa forma, limites à atuação das partes, objetivando alcançar o desfecho pacífico do conflito. Com base nisso, consideramos que o uso deste tipo de material em uma situação educativa pode contribuir para a abordagem significativa das relações entre Ciência, Tecnologia, Sociedade e Ambiente (CTSA), visto que embasado em uma situação social concreta e complexa (FARIAS e CARVALHO, 2003).

Assim, além de despertar a atenção dos alunos, esses casos auxiliam a tornar mais clara a complexidade da realidade, defrontando a problemática ambiental com diversas faces da vida social, como a política, a ciência, a tecnologia, a ética, a cultura etc. Ao mesmo tempo, a experiência da controvérsia põe em xeque as verdades absolutas e os mitos, dando lugar ao exercício da argumentação e do convencimento. Acrescenta-se, ainda, que os temas controversos fazem parte do cotidiano de todos nós, já que não existem consensos possíveis sobre várias questões atuais, como, por exemplo, as problemáticas relacionadas à vida, à saúde, às biotecnologias, ao ambiente (KOLSTO, 2001).

Consideramos, nesse sentido, que certos casos têm o potencial de educar porque revelam aspectos significativos e contextualizados da realidade. Do mesmo modo, Mayer (1998) considera útil para a EA o paradigma indiciário proposto por Ginzburg (1986), por meio do qual são construídas histórias que sejam coerentes internamente e adequadas aos indícios que se tem à disposição e que permitem trazer à tona significados que, de outro modo, permaneceriam velados. O modelo de racionalidade que informa o paradigma indiciário é a da reconstrução de histórias, totalmente únicas e, portanto, particulares. A semelhança que existe entre o paradigma indiciário e o uso educativo de casos, é que ambas as propostas procuram, nas situações da realidade, o contexto e as relações complexas entre as partes que a compõem. Esta característica parece se adequar a um dos objetivos da EA, que é o de construir conhecimentos sem reduzi-los a esquemas disciplinares. A este respeito, Shulman (1992) acrescenta que os casos têm o potencial de ensinar princípios ou conceitos teóricos, precedentes para a prática, princípios morais ou éticos, estratégias de determinadas práticas profissionais, visões ou imagens do possível, além de diminuir a distância entre a realidade e os conhecimentos teóricos. 
Como em outros casos controversos, os conflitos socioambientais podem apresentar diferentes perspectivas, mantendo-se, conseqüentemente, abertos a diferentes soluções, pois implicam temas que estão na fronteira do conhecimento. Este aspecto estimula os envolvidos à tomada de posição e possibilita o exercício da argumentação e do convencimento em relação às teses debatidas. É importante reconhecer que a sociedade é permeada por debates, sendo, portanto, a linguagem e a argumentação aspectos fundamentais da organização social. Nos conflitos judiciais, é visível a oposição entre interesses, o debate sobre direitos, os procedimentos técnicos considerados válidos e os tipos de provas cabíveis. Em situações dessa natureza, a argumentação é central, pois é por meio dela que os conflitos são interpretados.

No presente trabalho, focalizamos os discursos jurídicos do processo judicial mencionado, utilizando a interpretação hermenêutica dos argumentos (PERELMAN, 1996, RICOEUR, 1983). De acordo com Perelman e Olbrechts-Tyteca (1996), o objetivo de toda argumentação é provocar ou aumentar a adesão dos ouvintes às teses que lhes são apresentadas. Uma argumentação é eficaz quando consegue aumentar a intensidade de adesão, de forma a desencadear nos ouvintes a ação pretendida (ação positiva ou abstenção) ou, pelo menos, criar neles uma disposição para a ação. A revalorização da retórica proposta por Perelman e Olbrechts-Tyteca (1996) pressupõe a afirmação de que a discussão e o debate são partes fundamentais da racionalidade humana, pois é por meio da argumentação que as pessoas manifestam suas razões. Segundo Silveira (1998, p. 25) a proposta de Perelman (1996) contrapõe-se ao formalismo lógico, de tradição cartesiana, que pretendia limitar a razão ao campo do cientificismo, das verdades demonstráveis, “[...] a um modelo racional monológico que desconsiderou como irracional ou ilógico tudo aquilo que estivesse fora do raciocínio formalizado".

No debate judicial, o que pode ser considerado um fato raramente é uma realidade incontestável. Também é difícil fazer distinção entre fatos e valores, pois os valores intervêm ao longo de todo raciocínio jurídico, inclusive na qualificação dos fatos e da definição dos textos legais que lhe são aplicáveis. Por outro lado, segundo Perelman (1996), o que permite sustentar a existência de um fato, apesar da posição contrária de um adversário, são as suas condições de verificação, ou seja, havendo concordância quanto às provas, o fato não controverso tende a assumir o sentido de uma premissa para as partes envolvidas. Por outro lado, o "estabelecimento dos fatos é submetido às regras processuais e da prova que o juiz não pode transgredir", o que, freqüentemente, resulta na apartação da realidade concreta à qual se referem (PERELMAN, 1996, p. 573).

No processo em questão, o percurso argumentativo das partes - Ministério Público e CESP -, foi marcado pela tensão constante entre versões distintas a respeito daquilo que são considerados os fatos, os impactos originados pela formação do reservatório da UHE Três Irmãos, e, principalmente, do direito relacionado à responsabilidade da empresa ré diante destes impactos e da legislação cabível ao caso. Vale lembrar que o texto jurídico sempre é passível de interpretação, e não há clareza textual suficiente que dispense o trabalho interpretativo. Para Perelman (1996, p. 622) “[...] uma regra de direito é necessariamente interpretada dentro do contexto de um sistema jurídico, e este pode obrigar-nos a introduzir, na leitura do texto, cláusulas gerais que lhe restringem o alcance, mas que não estão explicitadas". No entanto, para o autor citado, pode-se considerar um texto claro quando todas as interpretações razoáveis que dele se poderiam tirar conduzem a uma mesma solução, o que não acontece em casos excepcionais ou inovadores, quando a regra jurídica pode dar azo a interpretações divergentes. 
Da análise deste caso, resultou um texto que serviu como material pedagógico em um minicurso ministrado a alunos do Ensino Médio de uma escola pública. Esse material foi composto por sínteses de textos selecionados, tais como: a petição inicial da Ação Civil Pública Ambiental n. 097/90, movida pelo Ministério Público do Estado de SP; o Relatório de Impacto Ambiental (Rima); a contestação da Companhia Energética de São Paulo (CESP); manifestações diversas de representantes da sociedade civil; informações e pareceres técnicocientíficos; decisões judiciais; além das alegações finais das partes, recursos e acórdãos proferidos pelo Tribunal de Justiça de São Paulo (TJSP) e pelo Superior Tribunal de Justiça (STJ). A elaboração desse texto-síntese destinou-se a narrar didaticamente o trajeto do debate firmado nesse processo judicial e, do nosso ponto de vista, trata-se de um caso exemplar de confronto entre uma concepção dominante de desenvolvimento e a emergência dos discursos jurídicos ambientalistas de defesa e proteção ambiental.

\section{O caso judicial da UHE Três Irmãos: relações entre Ciência, Tecnologia, Sociedade e Ambiente}

O texto-síntese elaborado com base no caso judicial da UHE Três Irmãos foi constituído por uma narrativa a respeito dos principais aspectos da trajetória processual e da argumentação presente nos discursos das partes litigantes e do Judiciário, além de outras informações consideradas pertinentes ao processo educativo, como, por exemplo, a caracterização geral do empreendimento tecnológico, o contexto temporal e espacial de sua construção e a legislação ambiental relacionada ao caso. Vale dizer que a UHE Três Irmãos é uma grande barragem situada no último trecho do rio Tietê, a $28 \mathrm{~km}$ do seu encontro com o rio Paraná, no interior do Estado de São Paulo, entre os municípios de Andradina e Pereira Barreto. É a maior usina construída no rio Tietê. O referido processo judicial teve início na década de 1990, época em que começava a se multiplicar o uso de recursos judiciais para a defesa ambiental e o Ministério Público se consolidava como a instituição autora por excelência em processos dessa natureza.

Nesse processo, o Ministério Público pretendia, por meio da Ação Civil Pública Ambiental, que a CESP não iniciasse a formação do reservatório da UHE Três Irmãos até que fossem aprovados, pelo órgão estadual competente, o respectivo Estudo de Impacto Ambiental e Relatório de Impacto Ambiental (EIA/Rima) e o Licenciamento Ambiental, bem como fossem cumpridas, pela empresa, todas as medidas preventivas ou mitigadoras dos impactos ambientais que afetariam, sobretudo, o município de Pereira Barreto, além de outros vários municípios da região. Além disso, esperava que o Judiciário condenasse a CESP a pagar uma indenização para subsidiar a reposição das áreas de vegetação que seriam destruídas com a formação do reservatório. Por sua vez, na contestação, a ré enfatizava razões de direito que, supostamente, impediriam o julgamento de mérito da ação e, a este respeito, argumentava que suas atividades estavam de acordo com as determinações legais e administrativas vigentes na época em que se iniciaram as obras para a construção da usina hidrelétrica.

No decorrer do processo, porém, intervieram vários atores sociais implicados com essa problemática, entre os quais agentes políticos e representantes de organizações da sociedade civil, atentos aos desdobramentos que esse caso gerava na esfera da administração públi- 
ca, especialmente, do licenciamento ambiental do empreendimento. No mesmo ano em que foi instaurada essa ação judicial, 1990, o órgão ambiental aprovou o EIA/Rima, bem como os programas de monitoramento e de proteção ambiental e as medidas de mitigação dos impactos socioambientais negativos, sendo, em conseqüência, expedida a Licença de Operação da UHE Três Irmãos. Diante desse fato, em agosto do mesmo ano, o Judiciário admitiu a formação do referido reservatório até a cota 310 metros, advertindo que não poderiam ser prejudicados os programas previstos no EIA/Rima.

Além disso, vários debates destacaram-se no percurso processual, como, por exemplo, a pressão de certos setores sociais afetados pela interferência da UHE na região, e inúmeros desacordos quanto aos resultados das medidas de minimização dos impactos socioambientais, entre as quais: os programas relacionados ao salvamento de animais ameaçados de extinção, a qualidade das águas e a infra-estrutura. No entanto, convencido da existência de danos ambientais concretos, o juiz da primeira instância decidiu pela necessidade de um parecer técnico-científico, inclusive, para informar o valor da indenização que deveria ser suportada pela empresa ré. Além da caracterização da área de influência do reservatório, a perícia judicial avaliou que o volume do reservatório chegaria, aproximadamente, a 14 bilhões de $\mathrm{m}^{3}$ e inundaria $817 \mathrm{~km}^{2}$, exigindo a retirada de florestas, afetando o micro-clima da região, atingindo áreas de procriações, a qualidade das águas, enormes áreas de várzeas e inúmeras espécies vegetais e animais. Concluiu, também, que seria necessário reflorestar as margens do reservatório da UHE Três Irmãos e dos seus principais tributários, visando compor uma mata ciliar. A este parecer, foi acrescentado o do assistente técnico do Ministério Público, argumentando a respeito da importância ecológica das áreas alagadas, bem como dos impactos de ordem cultural, visto que seriam atingidos aspectos da história da cultura e dos modos de vida local. Divergindo destes pareceres, a CESP ofereceu a sua perspectiva técnico-científica, pela qual denunciava a parcialidade dos pareceres anteriores e articulava argumentos que, entre outros aspectos, davam ênfase às ações e aos programas de reparação ambiental empreendidos pela empresa. Tal debate, envolvendo os pareceres técnicos, constituiu um dos principais instrumentos de que dispôs o Judiciário para se pronunciar a respeito do conflito. No entanto, as informações científicas levadas ao processo estabeleceram poucos consensos e revelaramse bastante contraditórias, intensificando a oposição entre os debatedores e deflagrando a natureza política das teses em confronto.

Apesar disso, a decisão judicial tomada na Comarca de Pereira de Barreto, em 1992, considerou que as perdas ambientais decorrentes do empreendimento foram muito expressivas e que os dois primeiros pareceres constituíam fontes seguras de informações e, portanto, adequadas para embasar a sua decisão. Neste sentido, o juiz julgou procedente a Ação Civil Pública Ambiental proposta pelo Ministério Público, condenando a CESP ao pagamento de vultosa indenização pelos danos causados ao ambiente, a qual deveria reverter em favor da recuperação ambiental da área atingida. Desta decisão, a CESP, inconformada, recorreu aos tribunais, utilizando, entre outros argumentos, o de que a realidade social brasileira não admitiria o sacrifício da produção industrial e do progresso da nação em nome da proteção ambiental.

Por sua vez, a Quinta Câmara Cível do TJSP, por votação unânime, decidiu acolher o recurso da CESP e modificar completamente a sentença do juiz de Pereira Barreto, julgando improcedente a ação. Para os desembargadores, não havia como qualificar a CESP como um agente de danos ao meio ambiente, em vista da autorização governamental da obra e dos 
programas ambientais a ela relacionados. Também concordaram com o argumento de que o poder público agiu com seu poder de decisão e dentro da legalidade. Essa nova situação levou várias organizações não-governamentais $(\mathrm{ONG})$ e a própria Procuradoria Geral da Justiça a ingressassem em juízo para recorrerem do referido acórdão. No entanto, tais iniciativas não resultaram em um novo julgamento pelo STJ por razões de natureza estritamente processual.

Este caso judicial, na nossa perspectiva, propicia várias reflexões sobre relações CTSA, visto que traz à tona a problemática do desenvolvimento econômico e tecnológico em face das atuais demandas socioambientais. Além disso, remete a uma questão bastante atual que é a energética, cuja complexidade exige que se levem em consideração os impactos locais e globais. Por outro lado, o caso também revela aspectos do direito ambiental que merecem toda a atenção da sociedade, como, por exemplo, a distância interpretativa que se observa entre os julgamentos judiciais provenientes dos locais onde se vivem os dramas socioambientais e aqueles proferidos pelos tribunais em segunda instância. Esta consideração é útil para que se compreenda que o Direito Ambiental não representa apenas um conjunto de leis ambientais a serem formalmente aplicadas, mas que constitui, sobretudo, um tipo de racionalidade ambiental que ainda não logrou permear a cultura jurídica brasileira e, conseqüentemente, as jurisprudências dos tribunais.

Neste sentido, o uso deste caso para a educação pode criar condições para que se explorem questões que, de outro modo, não se dariam a conhecer. São contextos, problemas, valores e argumentos que entram em jogo de maneira articulada e indissociável, extrapolando as superadas abordagens individualistas diante da problemática ambiental e inserindo, na educação, certas dimensões do conhecimento ainda pouco presentes na escola.

\section{A experiência do minicurso "O Direito Ambiental na Escola"}

A experiência educativa que aqui descrevemos é a de um minicurso de trinta horas realizado com alunos das primeiras e segundas séries do Ensino Médio da Escola Estadual de Urubupungá (Ilha Solteira, SP) nos meses de novembro e dezembro de 2002. Os participantes eram alunos com idades entre 14 e 17 anos, que aderiram voluntariamente ao minicurso, oferecido em horário alternativo às aulas regulares da escola. A proposta de realização desse minicurso foi bem recebida na escola e contou com a valiosa colaboração de uma professora interessada em práticas educativas inovadoras.

No planejamento e execução do minicurso, foi conferida uma especial atenção à forma e ao conteúdo do assunto, cuidando-se para trazer para o contexto escolar elementos capazes de propiciar uma vivência educativa significativa sobre um debate jurídico-ambiental. Deste modo, optamos pela dramatização das principais etapas do processo judicial, o que implicou o desempenho, pelos alunos participantes, de papéis referentes ao Poder Judiciário, ao Ministério Público (autor), e à CESP (ré), além de outros intervenientes, como os representantes de ONGs.

Além do texto-síntese do processo judicial em questão, também foram utilizados textos de apoio considerados úteis para a compreensão do assunto, como, por exemplo: a Constituição Federal de 1988, textos legais e conceituais sobre o EIA/Rima, a Política Nacional do Meio Ambiente, o Sistema Nacional do Meio Ambiente, o Sistema Estadual do Meio 
Ambiente do Estado de São Paulo, a função institucional do Ministério Público e a Ação Civil Pública Ambiental.

No decorrer dos encontros, foram estudadas, debatidas e dramatizadas "cenas" do caso judicial da UHE Três Irmãos, de modo que, ao final do minicurso, havíamos passado pelas várias etapas do processo até sua conclusão com o acórdão proferido pela instância superior. A dinâmica dos encontros incluiu: exposições dialogadas sobre o processo judicial, leitura e interpretação de textos, trabalhos em pequenos grupos, preparação e execução da dramatização, e avaliação ao final de cada encontro. De modo geral, observamos grande interesse dos alunos em dramatizar e se posicionar diante do impasse revelado nesse conflito.

\section{Análise e discussão dos significados atribuídos pelos alunos}

A análise da vivência educativa embasou-se na interpretação fenomenológica dos significados atribuídos pelos alunos. Para a fenomenologia, a consciência ativa e reflexiva é a consciência intencional. Ao se dirigir aos significados, o foco da pesquisa fenomenológica não está nos fatos tais como podem ser observados pelo pesquisador, mas sim naquilo que os sujeitos têm a dizer a respeito de determinados eventos ou vivências. Com base neste ponto de vista, a atribuição de significados é o centro da pesquisa e da aprendizagem.

A entrevista foi o instrumento utilizado neste trabalho para se obterem descrições informais dos alunos a respeito do evento enfocado. Nessa fase, participaram seis alunos. A entrevista foi norteada por questões abertas, permitindo aos alunos narrarem livremente suas percepções sobre a experiência vivenciada. No começo de cada entrevista, apresentava-se uma questão solicitando ao entrevistado uma descrição geral do minicurso e, na seqüência, eram feitas questões a fim de se aprofundarem certos aspectos já mencionados pelos entrevistados ou conduzi-los a tematizar sobre aspectos considerados por nós importantes, tais como: conte sobre a dramatização do conflito judicial e sobre os papéis que você desempenhou. O que foi mais importante para você neste minicurso? Como você avalia a aplicação do direito ambiental neste caso?

Assim, o procedimento de análise das descrições obtidas implicou a transcrição das entrevistas e sucessivas leituras dos discursos dos sujeitos para a constituição das unidades de significado, formadas com base na seleção e interpretação de fragmentos dos discursos individuais. Em um segundo momento, passou-se à compreensão do significado coletivo do fenômeno por meio da chamada análise nomotética. Segundo Carvalho (1991), a análise nomotética interessa-se em buscar as convergências e divergências entre as essências dos discursos individuais. É um processo de interpretação que procura trazer à luz as idéias comuns e discrepantes no conjunto dos discursos dos sujeitos. O objetivo dessa análise foi buscar reconhecer quais os significados pessoais atribuídos pelos alunos ao minicurso, bem como sua importância para uma vivência significativa em Educação Ambiental. Tomando por base esse objetivo, procuramos ampliar o escopo do trabalho, indagando sobre que perspectivas educativas que essa experiência poderia sugerir.

As unidades de significado foram agrupadas, primeiramente, em categorias convergentes, chamadas categorias iniciais, e estas embasaram a formação das categorias amplas que, por sua vez, constituíram as categorias gerais. Esta última categoria de significados visou nortear a discussão e oferecer uma visão abrangente do fenômeno investigado. 
Para mostrar o trajeto interpretativo realizado, tomamos, como exemplo, o processo de formação de uma categoria ampla, a CA.2 - O caso judicial ambiental auxiliou na percep̧̧ão da relação entre desenvolvimento e sustentabilidade (Quadro 1). Esta categoria foi formada com base em uma única categoria inicial (CI-8), indicativa das convergências discursivas em torno da inclusão da dimensão ambiental no conceito de desenvolvimento. É uma síntese interpretativa de um conjunto de unidades de significado presente nos discurso de três entrevistados: $o$ desenvolvimento é aceitável quando considera o cuidado da natureza; o desenvolvimento deve evitar prejuizos ao ambiente; é possivel desenvolver sem degradar o ambiente (entrevista 1). O desenvolvimento nem sempre é benéfico; as indústrias são diferentes entre si: algumas são mais sustentáveis do que outras; vivemos em uma sociedade capitalista que não busca a sustentabilidade (entrevista 2). É preciso minimizar a degradação ambiental; épreciso restabelecer o equilibrio perdido; as grandes empresas deveriam ser responsáveis (entrevista 3). Estas unidades de significado revelam a constituição de uma idéia de desenvolvimento que não prescinde das questões ambientais, ainda que esta seja uma problemática bastante controversa na nossa sociedade. Por outro lado, os discursos são também reveladores de uma intenção crítica sobre essa relação, questionando o fato de vivermos em "[...] um mundo muito capitalista [...]" em que desenvolvimento apresenta-se como um conceito ambíguo.

Em razão das dimensões do presente trabalho, no Quadro 1 apresentamos categorias amplas e gerais construídas com base em nossa análise:

\begin{tabular}{|c|c|}
\hline Categorias gerais & Categorias amplas \\
\hline \multirow{6}{*}{$\begin{array}{l}\text { A. O caso judicial ambiental favoreceu } \\
\text { a percepção da complexidade do } \\
\text { conflito socioambiental. }\end{array}$} & $\begin{array}{l}\text { CA.1. O uso educativo do caso judicial ambiental possibilitou a } \\
\text { tematização de diversas relações socioambientais. }\end{array}$ \\
\hline & $\begin{array}{l}\text { CA.2. O caso judicial ambiental auxiliou na percepção da relação } \\
\text { entre desenvolvimento e sustentabilidade. }\end{array}$ \\
\hline & $\begin{array}{l}\text { CA.3. A abordagem educativa do caso judicial ambiental favoreceu a } \\
\text { atribuição de significados ao direito ambiental. }\end{array}$ \\
\hline & $\begin{array}{l}\text { CA.4.O conhecimento mais aprofundado do caso possibilitou } \\
\text { posicionamentos em relação à controvérsia judicial. }\end{array}$ \\
\hline & $\begin{array}{l}\text { CA.5. O estudo do caso judicial ambiental trouxe, para a esfera } \\
\text { escolar, dimensões jurídica e judicial do conflito ambiental. }\end{array}$ \\
\hline & $\begin{array}{l}\text { CA.7. O caso judicial ambiental estimulou reflexões sobre a questão } \\
\text { energética. }\end{array}$ \\
\hline $\begin{array}{l}\text { B. O uso da dramatização como } \\
\text { ferramenta educativa propiciou o } \\
\text { aprendizado significativo do Direito } \\
\text { Ambiental. }\end{array}$ & $\begin{array}{l}\text { CA.8. A dramatização contribuiu para a atividade de EA ser } \\
\text { considerada significativa. }\end{array}$ \\
\hline $\begin{array}{l}\text { C. A atividade educativa despertou o } \\
\text { interesse pelas ações dirigidas à } \\
\text { conquista e ao exercício dos direitos } \\
\text { de cidadania ambiental. }\end{array}$ & $\begin{array}{l}\text { CA.9. A atividade de EA, baseada em um conflito de Direito } \\
\text { Ambiental, despertou interesse para ações de conquista e exercício } \\
\text { de cidadania. }\end{array}$ \\
\hline
\end{tabular}

Quadro 1. Apresentação nomotética. 


\section{A percepção da complexidade do conflito socioambiental}

A primeira categoria geral (A) desvela um importante potencial atribuído ao uso educativo do caso, que se refere à percepção da complexidade que caracteriza a realidade socioambiental. Quando falamos em complexidade, fazemos referência a uma forma de pensamento que procura superar a tradicional fragmentação do conhecimento e das ciências (MORIN, 2000), a fim de possibilitar uma leitura do mundo que contemple as relações e interações socioambientais. Assim, perceber a complexidade do conflito socioambiental significa compreender, não só a multiplicidade das dimensões que compõe um determinado fenômeno, mas, especialmente, reconhecer as articulações que existem entre essas dimensões e entre os fenômenos sociais e seus contextos temporais e espaciais.

Neste trabalho, identificamos alguns elementos, nos discursos dos alunos, que nos conduzem a fundamentar o uso do caso judicial como uma estratégia educativa capaz de levar para a escola o Direito Ambiental sem reduzi-lo ao esquema disciplinar, mas sim considerando a complexidade que permeia o processo de resolução de um determinado conflito socioambiental. Tais elementos são diversos, conforme o Quadro 1, e nos permitem construir uma perspectiva educativa ampla sobre a inclusão do Direito Ambiental como componente da Educação Ambiental que necessitamos.

O primeiro elemento que destacamos refere-se à "tematização de diversas relações socioambientais" (CA.1). De modo geral, as descrições oferecidas pelos alunos incluíram também questões referentes a problemas e conflitos socioambientais ligados, notadamente, ao contexto local, à qualidade do ambiente e à qualidade de vida. Dessa forma, o caso judicial, objeto de estudo no minicurso, criou uma oportunidade para que os alunos refletissem, além da problemática específica relativa à UHE de Três Irmãos, sobre várias outras questões envolvendo a construção de um conceito ampliado de meio ambiente, a avaliação das condições do ambiente onde vivem, bem como das relações socioambientais que aí se estabelecem.

Por outro lado, a análise fenomenológica também revelou que os conflitos foram menos mencionados pelos sujeitos do que os problemas socioambientais, sendo estes últimos associados ao desmatamento, à poluição das águas, aos loteamentos em área de preservação permanente, ao lixo, às queimadas e a certas condutas de pesca. Quanto ao potencial de ensino relacionado a esta categoria, nos discursos de alguns entrevistados, destaca-se o interesse por conteúdos que, normalmente, não estão presentes na sala de aula e que, além disso, encontramse na fronteira das disciplinas e áreas científicas, como no caso dos conflitos socioambientais. Entre as implicações de se tratar com assuntos dessa natureza no ensino, observa-se a existência de várias perspectivas que se abrem à resolução de uma controvérsia. A este respeito, Herreid (1997) ressalta que, sobre um mesmo caso, diferentes grupos percebem aspectos diversos e, por isso, é provável que tenham concepções também diversas acerca da sua solução.

Outra compreensão extraída das entrevistas refere-se ao reconhecimento da relação entre desenvolvimento e sustentabilidade, confrontando a necessidade de geração de energia elétrica, considerada fator fundamental para o desenvolvimento, e a insurgente preocupação ambiental, associada à construção de uma idéia de sustentabilidade socioambiental (CA.2). Entendemos que a abordagem educativa desta relação introduziu os alunos a uma postura diante da problemática ambiental na qual está inserido o caso da UHE Três Irmãos, relacionando-a com a atual discussão que se faz em torno do conceito do desenvolvimento sustentá- 
vel e as responsabilidades a serem assumidas pelos poderes públicos e privados em face dos crescentes desafios socioambientais.

Juntamente com estes aspectos, também foi significativa a inserção do Direito Ambiental na atividade educativa (CA.3). Esta categoria foi formada com base em unidades de significado que valorizaram a inclusão das normas legais e constitucionais de proteção ambiental, assim como dos temas em torno da função instrumental do direito ambiental, os deveres dos poderes públicos e os direitos individuais em face das novas demandas jurídico-ambientais. Destaca-se que este significado provém do estudo do caso judicial referente à UHE Três Irmãos, o que nos permite fazer inferências positivas a respeito do uso de um caso para ensinar Direito Ambiental na Educação Básica, visto que os casos são capazes de contextualizar os temas jurídicos, colaborando para que os alunos atribuam sentidos a essa prática social.

Por outro lado, considera-se que a dimensão ambiental no campo jurídico representa, hoje, uma importante conquista dos movimentos ambientalistas, configurando o Direito Ambiental como um dos principais instrumentos de solução pacífica dos conflitos desta matéria. Levar esta temática para o currículo do Ensino Médio significa, assim, inserir um importante conteúdo cultural na formação básica, diminuindo a distância que existe entre o conhecimento especialista e o dos cidadãos em geral. É importante ponderar, ainda, que o "mundo do direito", historicamente, tem se mantido incompreensível para a maioria das pessoas, apesar dos reconhecidos avanços em termos legais e constitucionais. Neste sentido, torna-se pertinente que os conhecimentos escolares contribuam para que os estudantes tenham acesso à dimensão ético-jurídica da cultura contemporânea, para que possam planejar e empreender ações mais efetivas em defesa de seus direitos coletivos.

Relacionada a este aspecto, a quarta categoria ampla enuncia que o conhecimento mais aprofundado do caso possibilitou aos alunos posicionarem-se em relação à controvérsia judicial (CA.4), assim como avaliarem a legitimidade dos argumentos das partes no conflito e das decisões do Judiciário. Esse aspecto constituiu, também, uma oportunidade para idealizarem outro desfecho ao caso prático, exercitarem o pensamento reflexivo e proporem suas alternativas embasadas em princípios e valores adotados pessoal e coletivamente. Desta forma, estes elementos auxiliaram na construção, pelos alunos, de uma idéia acerca da cultura jurídica, bem como da linguagem e dos procedimentos próprios do campo jurídico (CA.5). Por outro lado, de acordo com a análise efetuada, embora a experiência tenha contribuído para o entendimento de certos termos e expressões desse campo, ao mesmo tempo, apresentou dificuldades, uma vez que, pertencendo a um campo altamente especializado, foi constituída para se manter hermética aos que nesta linguagem não foram iniciados. Os discursos dos alunos confirmam esta condição de difícil acesso à interpretação do direito, mas, também, revelam que a Educação Básica pode ser uma via válida para uma maior abertura da cidadania aos instrumentos jurídicos oficiais.

De modo convergente aos aspectos mencionados, o conflito judicial abordado favoreceu a tematização de uma questão crucial no mundo contemporâneo, que é a energia (CA.7). Ressalta-se que as atuais discussões que ocorrem em todo o mundo, sobre as fontes e as formas de obtenção de energia elétrica, cada vez mais, transcendem os muros do saber técnico especializado, tornando-se questões fortemente dependentes do aval político e jurídico. No presente trabalho, o caso judicial relativo aos impactos socioambientais da UHE de Três Irmãos é exemplar de uma problemática que não é só brasileira e que mobiliza setores governa- 
Farias, C. R. O.; Carvalho, W. L. P.

mentais e não governamentais em torno da definição de políticas para esta matéria. O problema é que, embora as usinas hidrelétricas sejam consideradas uma alternativa energética, no Brasil, com freqüência, esta opção tem-se revelado social e ambientalmente insustentável. Do mesmo modo, ainda que hoje se possa afirmar existirem marcos legais e administrativos que sinalizem a superação da visão tecnocrática e centralizadora que caracterizou as decisões políticas no campo desses empreendimentos em outras décadas, permanecem graves problemas relacionados ao acesso e à equidade na distribuição dos serviços energéticos, conferindo maior complexidade a este debate (BERMANN, 2002; VALÊNCIO et al., 1999).

De modo geral, o conjunto das categorias apresentadas converge no sentido da complexidade, visto que a problemática ambiental e energética requer considerações teóricas e metodológicas que considerem, ao mesmo tempo, aspectos objetivos e subjetivos, cognitivos e axiológicos. Segundo Delgado (2003), o conhecimento complexo é simultaneamente um conhecimento externo (do mundo, do entorno, da natureza) e interno (relativo ao sujeito que conhece). Além disto, o autor considera que o principal problema ambiental da chamada sociedade ocidental é o valor atribuído ao ambiente, razão pela qual o desafio da educação de hoje é se confrontar com o problema dos limites culturais, proporcionando às pessoas "um marco teórico integrador que permita a orientação dos sujeitos com o complexo sistema de interações cognitivas, econômicas, políticas e ideológicas” (DELGADO, 2003, p. 20).

\section{A dramatização como vivência educativa}

A segunda categoria geral (B) refere-se ao uso da dramatização como ferramenta para um aprendizado significativo. Esta categoria foi formada valendo-se de um conjunto de unidades de significados que inclui: o papel da dramatização como facilitadora do processo de aprendizagem; o prazer associado às atividades de dramatização; e a construção ativa e significativa da aprendizagem.

Para os alunos, o uso da dramatização conferiu um maior sentido de realidade aos temas tratados, uma melhor compreensão do conflito em questão, assim como facilitou o ensino e o aprendizado ao transcender as abordagens puramente teóricas. A posição ativa dos alunos diante do seu próprio processo de aprendizagem também foi enfatizada nos discursos dos entrevistados: envolvimento da maioria dos alunos nas atividades de dramatização, oportunidades para se manifestarem livremente, uma rotina que valorizava as interpretações individuais e coletivas, assim como a espontaneidade na adesão às atividades. Segundo Driver et al. (1999), na perspectiva do construtivismo social, a aprendizagem é um processo que comporta a inter-relação entre vários fatores da experiência pessoal, da linguagem e da socialização.

Vale ressaltar que, desde o início do trabalho, trabalhava-se com a hipótese de que a dramatização seria útil para dar visibilidade ao caráter simbólico dos procedimentos jurídicos. No entanto, com o desenvolvimento da pesquisa, não só confirmamos esta expectativa, como, também, compreendemos que a dramatização significou mais do que o envolvimento com procedimentos e linguagens jurídicas, mas criou um contexto educativo em que os alunos puderam explorar aspectos cognitivos, metodológicos e afetivos da aprendizagem. Além disso, mostrou-se ser um processo imaginativo e criativo, vinculado às representações que fazemos da realidade. 
Neste sentido, outro aspecto observado no presente trabalho, refere-se ao prazer proporcionado por essa estratégia educativa. O prazer é algo importante na vida e, portanto, também o é na aprendizagem. O prazer pode ser considerado uma sensação ou sentimento, que atende a uma necessidade vital, cuja satisfação procura-se naquilo que se faz. Consideramos que uma aprendizagem significativa também depende da relação de prazer experimentada e compartilhada pelos integrantes do grupo.

A dramatização, além do seu valor na elaboração de idéias, também contribuiu para a elaboração de imagens, organizadas com base em experiências vivenciadas, produzindo novos tipos de compreensões. Tal como a metáfora que, ao produzir a cena imaginada viabiliza a relação entre o que conhecíamos e o que estamos conhecendo, a dramatização possibilita interações que resgatam o sentido de interioridade com o mundo-vida ao permitir a conciliação entre cognição e sentido de prazer.

Assim, considera-se que a dramatização do caso judicial ambiental criou condições para uma atividade educativa significativa, por articular conhecimentos e prazer. Por outro lado, alguns alunos consideraram que esta poderia ser uma atividade ainda mais significativa se o tema a ser dramatizado surgisse espontaneamente do próprio grupo e por ele fosse também planejado. Nas entrevistas, os alunos demonstraram interesse em se manifestar mais integralmente por meio da dramatização, considerando-a como um espaço em que poderiam ser ainda mais ativos, escolhendo os casos, pesquisando, planejando, construindo argumentos e desempenhando a dramatização por meio de seus próprios julgamentos.

\section{Potência de ação dirigida à conquista e exercício da cidadania}

A categoria geral C - A atividade educativa despertou o interesse pelas ações dirigidas à conquista e ao exercício dos direitos de cidadania ambiental - foi formada valendo-se das seguintes categorias iniciais: o trabalho educativo com base em questões socioambientais locais revelou a tendência de ações para a defesa ambiental; a ação educativa mostrou-se uma possibilidade para o enfrentamento de problemas socioambientais locais; e a atividade educativa gerou perspectivas sobre o papel a ser desempenhado por uma ONG ambientalista no município.

Nas entrevistas, destacam-se unidades de significados relacionadas à importância de se conhecer o Direito Ambiental, ao desejo de atuar na defesa do ambiente, às conseqüências negativas da inércia social frente aos problemas socioambientais, à capacidade de cada um de contribuir com a melhoria das relações socioambientais, e ao exercício do direito de acesso à Justiça em matéria ambiental. No cerne desta categoria, está a idéia de que o Direito Ambiental pode constituir um conhecimento pertinente à formação e à motivação das pessoas para a ação social em defesa do ambiente local.

Por outro lado, os discursos dos alunos também nos sugerem que a participação no minicurso e a vivência educativa proporcionada pelo uso educativo de um caso judicial contribuíram para sua auto-identificação como sujeitos capazes de atuar, individual e coletivamente, para melhorar as relações socioambientais locais por meio de ações voltadas à conquista e ao exercício de direitos. Nos discursos dos alunos, foram apontadas desde ações relativas à formação ambiental da comunidade local até uma proposta mais ousada de organizar uma entidade ambientalista no município. Os conhecimentos relacionados ao Direito Ambiental foram 
considerados necessários para implementar essas ações, que têm o significado não só de romper com a "inércia" diante dos problemas ambientais, mas também de "catalisar" o potencial individual e coletivo do grupo para reivindicar direitos de cidadania ambiental.

De maneira geral, consideramos que esta categoria constitui uma perspectiva educativa bastante adequada às atuais reivindicações que se faz à EA, pois complementa os sentidos de formação e sensibilização ambiental, apontando para a possibilidade de formação para a ação coletiva de conquista e exercício da cidadania ambiental. Sem reduzir a EA a um mero instrumento de superação dos problemas da nossa atualidade, reconhece-se que a relação entre educação e cidadania é cada vez mais requerida, especialmente diante das demandas por mudanças na qualidade de vida daqueles mais afetados pelas contradições e desigualdades socioambientais. Hoje, há a compreensão de que cidadania vincula-se à idéia de aprofundamento da democracia e ampliação dos espaços de participação.

\section{Considerações finais}

Os comentários finais situam-se no horizonte entre o que se vivenciou durante a pesquisa e o que se acredita que ainda possa vir a ser realizado em futuras investigações e práticas educativas. Acreditamos que este é um campo profícuo porque cresce a importância do Direito Ambiental na sociedade, assim como na educação, porém ainda são escassas as pesquisas sobre esta relação, sobretudo no âmbito da escola. Além disso, consideramos que esta interface requer uma visão interdisciplinar que leve em conta, além de outras, as dimensões da ética, ciência, política, justiça etc. Assim, são necessários esforços para compreender a articulação desta interface, uma vez que não se trata apenas de mais um conteúdo específico a ser decodificado nas salas de aulas, mas sim de se aceitar o desafio de levar a complexidade dos fenômenos socioambientais para o cotidiano dos processos educativos escolares.

Entendemos que as três categorias gerais apresentadas neste trabalho se articulam às três dimensões consideradas relevantes para o aprendizado significativo: a primeira relativa aos temas; a segunda atinente às estratégias; e a terceira referente ao compromisso político. Estas três dimensões correspondem, respectivamente, à complexidade do conflito judicial ambiental, ao prazer experimentado pela dramatização, e à potência de ação dirigida à conquista e exercício da cidadania. Para nós, começa a se esboçar, mais claramente, a possibilidade da inclusão do Direito Ambiental como uma dimensão pertinente da ação Educativa Ambiental, de forma que esse não seja reduzido a um conjunto de normas ambientais, mas sim a uma janela pela qual se possa acessar a multidimensionalidade dos fenômenos socioambientais. Além disso, também consideramos necessário o aprofundamento teórico e prático das circunstâncias de aplicação do Direito Ambiental, sem descuidar de suas relações com a ciência, a ética, a política, e outros saberes sociais, com vistas a firmar, mais consistentemente, o terreno da intervenção educativa de natureza jurídico-ambiental no Ensino Médio.

\section{Agradecimento}

À Fundação de Apoio à Pesquisa do Estado de São Paulo (FAPESP), pela Bolsa de Mestrado (processo no. 01/05732-2). 
O direito ambiental na sala de aula: significados...

\section{Referências}

BERMANN, C. Energia no Brasil: para quê? Para quem? Crise e alternativas para um país sustentável. São Paulo: Livraria da Física: FASE, 2002.

BRASIL. MINISTÉRIO DA EDUCAÇÃO. Parâmetros Curriculares Nacionais: Ensino Fundamental. Brasília: MEC/SEF, 1998a.

SEF, 1998b.

. Parâmetros Curriculares Nacionais: Ensino Médio. Brasília: MEC/

CARVALHO, I. C. M. O ambiental como valor substantivo: uma reflexão sobre a identidade da EA. In: SAUVÉ, L.; ORELLANA, I.; SATO, M. (Orgs.). Textos escolhidos em Educação Ambiental: de uma América à outra. Montreal: Publications ERE-UQAM, 2002. p. $85-90$.

CARVALHO, W. L. P. Uma aproximação à compreensão do ensino de Ciências através de uma análise fenomenológica. Cadernos da Sociedade de Estudos e Pesquisa Qualitativos, São Paulo, v. 3, n. 3, p. 29-46. 1991.

. Cultura científica e cultura humanística: espaços, necessidades e expressões. 2005. 147f. Tese (Livre Docência) - Departamento de Física e Química, Faculdade de Engenharia de Ilha Solteira, Universidade Estadual Paulista, Ilha Solteira, 2005.

DELGADO, C. J. Complexidade e educação ambiental. In: GARCIA, R. L. (Org.). Método, métodos, contramétodo. São Paulo: Cortez, 2003. p. 9-23.

DRIVER, R. et al. Construindo conhecimento científico na sala de aula. Trad. Eduardo Mortimer. Química Nova na Escola, São Paulo, n. 9, p. 31-39, 1999.

FARIAS, C. R. O.; CARVALHO, W. L. P. Desvelando relações Ciência-TecnologiaSociedade-Ambiente a partir de um processo judicial sobre danos ambientais. In: ENCONTRO DE PESQUISA EM EDUCAÇÃO AMBIENTAL, 2., 2003, São Carlos. Anais... São Carlos: UFSCAR/Unesp Rio Claro/USP Ribeirão Preto, 2003. 1 CD-ROM.

GINZBURG, C. Miti, emblemi, spie. Einaudi: Turín, 1986.

HERREID, C. What is a case? Journal of College Science Teaching, [s.1.], v. 27, p. 92-94, 1997.

KOLSTO, S. D. Scientific literacy for citizenship: tools for dealing with the science dimension of controversial socioscientific issues. Science Education, [s.l.], v. 85, p. 291 310, 2001.

LAYRARGUES, P. P. Conflitos socioambientais e cidadania: qual é o tema da Educação Ambiental? In: MATA, S. F. et al. (Orgs.). Educação Ambiental: compromisso com a sociedade. Rio de Janeiro: M7 Editora, 1999. p. 50-55.

MARSHALL, T. H. Cidadania, classe social e status. Rio de Janeiro: Jorge Zahar, 1967. 
Farias, C. R. O.; Carvalho, W. L. P.

MAYER, M. Educación ambiental: de la acción a la investigación. Enseñanza de las Ciencias, Barcelona, v. 6, n. 2, p. 217-231, 1998.

MORIN, E. Saberes globais e saberes locais: o olhar transdisciplinar. Participação de Marcos Terena. Rio de Janeiro: Garamond, 2000.

PERELMAN, C. Ética e Direito. Trad. Maria Ermantina Galvão. São Paulo: Martins Fontes, 1996.

; OLBRECHTS-TYTECA, L. Tratado da argumentação: a nova retórica. Trad. Maria Ermantina Galvão. São Paulo: Martins Fontes, 1996.

RICOEUR, P. Interpretação e ideologias. Organização, tradução e apresentação de Hilton Japiassu. Rio de Janeiro: Livraria Francisco Alves Editora S/A, 1983.

SANTOS, M. E. V. Dos códigos de cidadania aos códigos do movimento CTS. In: MARTINS, I. P.; PAIXÃO, F.; VIEIRA, R. M. (Orgs.). Perspectivas Ciência-TecnologiaSociedade na inovação da educação em Ciência. Aveiro: Universidade de Aveiro, 2004. p. 13-21.

SHULMAN, L. S. Toward a pedagogy of cases. In: SHULMAN, J. H. (Org.). Case methods in teacher education. New York and London: Teachers College Press, Columbia University, 1992. p. 01-29.

SILVEIRA, R. Y. M. Ética e nova retórica. Revista Reflexão, Campinas, n. 70, p. 24-26, 1998.

VALÊNCIO, N. F. L. S. et al. O papel das hidroelétricas no processo de interiorização paulista: o caso das usinas hidroelétricas de Barra Bonita e Jurumirim. In: HENRY, R. (Ed.). Ecologia de reservatórios: estrutura, função e aspectos. Botucatu: Fundibio/Fapesp, 1999. p. 185-218.

VIEIRA, L. Cidadania e globalização. Rio de Janeiro: Record, 1997.

Artigo recebido em novembro de 2006 e aceito em abril de 2007. 